\title{
EFFECTS OF 3D NANOCOMPOSITE BIOCERAMIC SCAFFOLDS ON THE INMUNE RESPONSE
}

\begin{tabular}{|r|l|}
\hline Journal: & Journal of Materials Chemistry B \\
\hline Manuscript ID: & TB-ART-01-2014-000106.R3 \\
\hline Article Type: & Paper \\
\hline Date Submitted by the Author: & n/a \\
\hline Complete List of Authors: & $\begin{array}{l}\text { Cicuéndez, Mónica; Universidad Complutense, } \\
\text { Portolés, Pilar; Instituto de Salud Carlos III, } \\
\text { Montes-Casado, Maria; Instituto de Salud Carlos III, } \\
\text { Izquierdo-Barba, Isabel; Universidad Complutense, } \\
\text { Vallet-Regi, Maria; Universidad Complutense, } \\
\text { Portolés, María Teresa; Universidad Complutense de Madrid, Departamento } \\
\text { de Bioquímica }\end{array}$ \\
\hline
\end{tabular}


Madrid, 28-March-2014

Dear Editor:

Concerning our revised manuscript entitled "EFFECTS OF 3D NANOCOMPOSITE BIOCERAMIC SCAFFOLDS ON THE INMUNE RESPONSE" (Manuscript ID TB-ART-01-2014-000106.R2), we have taken the reviewer's comments into account and I am glad to send you the new revised version of the manuscript with the changes highlighted in green. The response to the reviewer 3 comments is included below.

Referee: 3

Comments to the Author

The present Fig. 11 and Fig. 13 look nice. The paper should be published by JMCB.

However, many persons use silica particles to stimulate immune response. In the present study "no significant difference was observed in the immune response in the presence or absence of MGHA". The difference maybe because the difference in sample morphology (one is nano particle, one is scaffold), in evaluation model, etc. Citation of the following papers and a brief discussion will significantly improve the importance and readability of the present paper.

1. Mahony D, Cavallaro AS, Stahr F, Mahony TJ, Qiao SZ, Mitter N. Mesoporous silica nanoparticles act as a self-adjuvant for ovalbumin model antigen in mice. Small. 2013 Sep 23;9(18):3138-46.

2. Wang $X$, Li $X$, Ito A, Sogo $Y$, Ohno T. Particle-size-dependent toxicity and immunogenic activity of mesoporous silica-based adjuvants for tumor immunotherapy. Acta Biomater. 2013 Jul;9(7):7480-9.

3. Vallhov H, Kupferschmidt N, Gabrielsson S, Paulie S, Strømme M, Garcia-Bennett AE, Scheynius A. Adjuvant properties of mesoporous silica particles tune the development of effector T cells. Small. 2012 Jul 9;8(13):2116-24.

Answer:

The studies concerning the adjuvant properties of mesoporous silica particles have been included in the revised manuscript (new references 46-48), explaining the different effects observed with nanoparticles and scaffolds, as referee 3 suggests.

I do hope you will consider the reviewed manuscript suitable for publication.

Thanking you very much for your attention, I remain

Sincerely yours 
Prof. M. Teresa Portolés

Departamento de Bioquímica y Biología Molecular I

Facultad de Ciencias Químicas

Universidad Complutense, 28040-Madrid, Spain

E-mail:portoles@quim.ucm.es 


\title{
Journal of Materials Chemistry B
}

\section{ARTICLE}

Cite this: DOI:

\section{Effects of 3D nanocomposite bioceramic scaffolds on the immune response}

\author{
Mónica Cicuéndez ${ }^{\mathrm{a}, \mathrm{b}}$, Pilar Portolés,d, María Montes-Casado ${ }^{\mathrm{d}}$, Isabel \\ Izquierdo-Barba $^{\mathrm{a}, \mathrm{b}}$, María Vallet-Regí ${ }^{\mathrm{a}, \mathrm{b}}{ }^{*}$ and María Teresa Portolés ${ }^{\mathrm{e}} *$
}

Received

Accepted

DOI:

www.rsc.org/
The interaction of new nanocomposite mesoporous glass/hydroxyapatite (MGHA) scaffolds with immune cells involved in both innate and acquired immunity has been studied in vitro as an essential aspect of their biocompatibility assessment. Since the immune response can be affected by the degradation products of bioresorbable scaffolds and scaffold surface changes, both processes have been evaluated. No alterations in proliferation and viability of RAW-264.7 macrophage-like cells were detected after culture on MGHA scaffolds which did not induce cell apoptosis. However, a slight cell size decrease and intracellular calcium content increase were observed after contact of this cell line with MGHA scaffolds or their extracts. Although no changes on the percentages of RAW cells with low and high content of reactive oxygen species (ROS) are observed by treatment with $7 \mathrm{~d}$ extracts, this study has revealed modifications of these percentages after direct contact with scaffolds and by treatment with 24h extracts, related to the high reactivity/bioactivity of this MGHA nanocomposite at initial times. Furthermore, when normal fresh murine spleen cells were used as an experimental model closer to physiological conditions, no significant alterations in the activation of different immune cell subpopulations were detected in the presence of 24h MGHA extract. MGHA scaffolds did not affect the spontaneous apoptosis or intracellular cytokine expression (IL-2, IL-10, IFN- $\gamma$, TNF- $\alpha$ ) either after $24 \mathrm{~h}$ treatment. The results obtained in the present study with murine immune cell subpopulations (macrophages, lymphocytes B, lymphocytes $\mathrm{T}$ and natural killer cells) supports the biocompatibility of MGHA material and suggests an adequate host tissue response to their scaffolds upon their implantation.

\section{Introduction}

Tissue engineering, due to its highly multidisciplinary nature, needs the combination of clinical medicine, mechanical engineering, materials science, genetics, and related disciplines from both engineering and life sciences. ${ }^{1}$ This field relies on the use of porous 3D scaffolds to provide the appropriate environment for the regeneration of tissues and organs. ${ }^{2}$ These scaffolds essentially act as a template for tissue formation and are seeded with cells and occasionally growth factors. The combination of cells, biomolecules and scaffolds constitute the tissue engineering triad. ${ }^{3}$

The composition, macroporous architecture, microporosity, surface topography and chemistry, as well as the mechanical properties of scaffolds used for tissue engineering play a crucial role in the success rates of implants. ${ }^{3}$ Fundamental aspects in the manufacturing process of $3 \mathrm{D}$ scaffolds are the starting material and the methodology which must be used for configuring the 3D structure. Different biomaterials are employed in the fabrication of scaffolds for tissue engineering, with specific advantages and disadvantages. Recently, the use of composite scaffolds allows improving their properties due to the synergy of the features of their components. For this reason, composite scaffolds are widely used for different applications. ${ }^{4-}$

${ }^{8}$ In this sense, our research group have recently synthesized a novel nanocomposite material formed by nanocrystalline apatite uniformly embedded into a mesostructured $\mathrm{SiO}_{2}-\mathrm{CaO}$ $\mathrm{P}_{2} \mathrm{O}_{5}$ glass wall (MGHA material). ${ }^{9}$ The response of $\mathrm{L} 929$ fibroblasts and Saos-2 osteoblasts to this powdered nanocomposite has been previously studied, demonstrating a significant improved biocompatibility in comparison with conventional mesoporous glasses. ${ }^{9,10}$ Furthermore, recently 3D scaffolds based on this nanocomposite material have been exhibited a good preosteoblast cell adhesion, colonization, proliferation and differentiation, suggesting their great potential application in bone tissue engineering. ${ }^{11}$

The first characteristic of any scaffold for tissue engineering is that it must be biocompatible, allowing the cell adhesion, proliferation and migration through it. ${ }^{12,13}$ However, the ultimate functional success or failure of the scaffolds after implantation, depends invariably on the host tissue response and therefore, the scaffold must not induce immune reaction which might reduce healing or produce rejection by the body. 
Thus, the in vitro evaluation of the biomaterial effects on immune system is an essential aspect of biocompatibility assessment. ${ }^{14}$ The immune response comprises both innate and adaptive defence mechanisms which activate different cell populations co-ordinately. The innate response involves the action of neutrophils, monocytes and macrophages which carry out phagocytosis and produce reactive oxygen species, antimicrobial peptides, and inflammatory mediators. ${ }^{15}$ Natural killer (NK) cells also play a role in the innate response by directly killing virus-infected or transformed cells without prior priming by secretion of cytotoxic molecules and cytokines. ${ }^{16}$ The adaptive response is mediated by antigen-specific lymphocytes ( $\mathrm{T}$ and $\mathrm{B}$ cells) which produce inflammatory cytokines and antibodies. ${ }^{15}$ Largely, the interaction of these host immune cells with biomaterials has negative implications for tissue remodelling. For decades, the interaction of macrophages with newly deposited extracellular matrix, accompanied by an angiogenic response, has been interpreted as a precursor of granulation tissue formation, the classic foreign body reaction, with negative implications for outcomes. ${ }^{17}$ However, it has been recently shown that macrophages may be beneficial for biomaterial integration improving implant performance due to a remarkable functional plasticity. Thus, macrophages can play both positive and negative roles in disease processes and tissue remodeling, presenting a phenotypic spectrum based on three fundamental homeostatic activities, including host defence, wound healing, and immune regulation. ${ }^{18}$ There are two extremes of possible macrophage phenotypes based on in vitro treatment with particular stimuli: proinflammatory (M1) and reparative (M2), ${ }^{17-20}$ whose balance determine the host response to biomaterials, with participation of diverse specific cytokines.

In this sense, the design of biomaterials capable of modulating immune cell function has been suggested in order to obtain appropriate host responses at implantation site. ${ }^{16-22}$

Given the excellent biocompatibility and bioactivity shown by the MGHA nanocomposite and taking into account its potential application in bone tissue engineering, ${ }^{9,11}$ the present study is focused on the in vitro interaction of 3D MGHA scaffolds with immune cells involved in both innate and acquired immunity. Furthermore, since the immune response can be additionally affected by the degradation products of bioresorbable scaffolds, the possible cytotoxic effects caused by MGHA extracts obtained at different times have been also studied.

\section{Materials and Methods}

\subsection{Preparation of MGHA 3D scaffolds}

MGHA 3D scaffolds based on highly mesostructured nanocomposite material were prepared by rapid prototyping (RP) using methylcellulose (MC), as previously reported. ${ }^{11}$ Once fabricated, these MGHA scaffolds were sterilized under UV light for $30 \mathrm{~min}$ and then submerged in Dulbecco's Modified Eagle's Medium (DMEM) supplemented with penicillin $(800 \mu \mathrm{g} / \mathrm{mL})$, streptomycin $(800 \mu \mathrm{g} / \mathrm{mL})$, under a $\mathrm{CO}_{2}$ (5\%) atmosphere at $37^{\circ} \mathrm{C}$ for $24 \mathrm{~h}$ to stabilize before cell culture.

\subsection{Characterization of MGHA 3D scaffolds}

X-ray diffraction (XRD) experiments were performed on a Philips X'Pert diffractometer (Eindhoven, The Netherlands), equipped with $\mathrm{Cu} \mathrm{K} \alpha(40 \mathrm{kV}, 20 \mathrm{~mA})$. Transmission electron microscopy (TEM) was performed on a JEOL 3010 electron microscope (Jeol Ltd., Japan) operating at $300 \mathrm{kV}$ (Cs; $0.6 \mathrm{~mm}$, resolution $1.7 \AA$ ). All TEM images were recorded employing a CCD camera (MultiScan model 794, Gatan Inc., UK) under low-dose conditions. Fourier transform (FT) patterns were extracted from the images of thin crystal regions using a Digital Micrograph (Gatan Inc., UK). Scanning electron microscopy (SEM) was performed using a field emission JEOL JSM-6335F microscope (Tokyo, Japan) at an acceleration voltage of $10 \mathrm{kV}$. The textural properties of samples were determined by $\mathrm{N}_{2}$ adsorption porosimetry using a Micromeritics ASAP2020 analyzer (Norcross, USA). The surface area was determined using the multipoint Brunauer-Emmett-Teller method included in the software. The porosity of 3D scaffolds was measured by mercury intrusion porosimetry in a MicromeriticsAutopore IV 9500 device (Micromeritics Instrument Corporation, Norcross, GA, USA). Elemental analyses $(\mathrm{C}, \mathrm{H}, \mathrm{N})$ were carried out on a LECO CHNS-932 microanalyzer (Saint Joseph, Michigan USA). Fourier transform Infrared (FTIR) spectroscopy was performed in a Thermo Nicolet Nexus spectrometer (Thermo Scientific, USA) from 4000 to $400 \mathrm{~cm}^{-1}$, using the $\mathrm{KBr}$ pellet method and operating in transmittance mode.

\subsection{In vitro degradation of MGHA 3D scaffolds and preparation of MGHA extracts}

MGHA scaffolds of ca. 23-25 mg, were immersed at different time periods during 30 days in a total volume of $100 \mathrm{~mL}$ of DMEM supplemented with $10 \%$ fetal bovine serum (FBS) and antibiotics (100 $\mathrm{U} \mathrm{ml}^{-1}$ penicillin, $100 \mathrm{mg} \mathrm{ml}^{-1}$ streptomycin), in a Ecotron at $37^{\circ} \mathrm{C}$ and 150 r.p.m. The supernatants obtained after $24 \mathrm{~h}$ and $7 \mathrm{~d}$, named E $24 \mathrm{~h}$ and E $7 \mathrm{~d}$, were selected for immune response studies. These extracts were filtered and added to RAW-264.7 macrophage-like cells to evaluate any potential cytotoxic effect. Determination of Si (IV), Ca (II) and $\mathrm{P}(\mathrm{V})$ variations in these extracts were carried out after different time intervals by inductively coupled plasma/optical emission spectrometry (ICP/OES) in a Perkin Elmer OPTIMA 3300 DV device. The scaffold surface was evaluated by scanning electron microcopy (SEM) after different times.

\subsection{Culture and treatment of RAW-264.7 macrophage-like cells}

Murine RAW-264.7 macrophage-like cells were seeded at a density of $10^{5}$ cells $/ \mathrm{mL}$ in culture medium supplemented with $10 \%$ FBS, $1 \mathrm{mM}$ L-glutamine, penicillin, streptomycin, under a $5 \% \mathrm{CO}_{2}$ atmosphere, at $37^{\circ} \mathrm{C}$ for $24 \mathrm{~h}$. Extract $24 \mathrm{~h}$ and $7 \mathrm{~d}$ have been also added to RAW macrophage-like cells to know the effects of the released products during the degradation process. Then, the attached cells were harvested with PBS/1mM EDTA at $4^{\circ} \mathrm{C}$ and counted with a Neubauer hemocytometer. Cell suspensions were centrifuged at $310 \mathrm{xg}$ for $10 \mathrm{~min}$ and resuspended in fresh medium for the analysis of different parameters by Flow Cytometry as described below (sections 2.5-2.8). Controls without treatment were carried out in parallel.

\subsection{Cell cycle analysis and apoptosis detection}

After detachment of RAW-264.7 macrophage-like cells, cell suspensions were incubated with Hoechst $33258(5 \mu \mathrm{g} / \mathrm{ml}$, ethanol $30 \%$, and BSA $1 \%$ in PBS), used as nucleic acid dye, for $30 \mathrm{~min}$ at room temperature in darkness. The fluorescence of Hoechst was excited at $350 \mathrm{~nm}$ and the emitted fluorescence was measured at $450 \mathrm{~nm}$ in a LSR Becton Dickinson Flow Cytometer. The cell percentage in each cycle phase $\left(G_{0} / G_{1}, S\right.$ and $\left.G_{2} / M\right)$ was calculated with the CellQuest Program of 
Becton Dickinson and the SubG $_{1}$ fraction (cells with fragmented DNA) was used as indicative of apoptosis.

\subsection{Cell size and complexity}

After detachment of RAW-264.7 macrophage-like cells, forward angle (FSC) and side angle (SSC) scatters were evaluated as indicative of cell size and complexity respectively using a FACScalibur Becton Dickinson flow cytometer.

\subsection{Intracellular reactive oxygen species (ROS) content and cell viability}

After detachment of RAW-264.7 macrophage-like cells, cell suspensions were incubated with $100 \mu \mathrm{M} 2^{\prime}, 7^{\prime}-$ dichlorofluorescein diacetate (DCFH/DA) at $37^{\circ} \mathrm{C}$ for $30 \mathrm{~min}$. DCF fluorescence was excited at $488 \mathrm{~nm}$ and measured with a $530 / 30 \mathrm{~nm}$ band pass filter in a FACScalibur Becton Dickinson flow cytometer. Cell viability was determined by addition of propidium iodide (PI; $0.005 \%$ in PBS).

\subsection{Intracellular calcium content}

After detachment of RAW-264.7 macrophage-like cells, cell suspensions were incubated with the probe Indo-1 AM at a concentration of $10 \mu \mathrm{M}$ for $30 \mathrm{~min}$ at room temperature, darkness, and shaking. The fluorescence of Indo-1 was excited at $325 \mathrm{~nm}$ and the emitted fluorescence was measured with 380 $\mathrm{nm}$ long pass (FL1) and 424/44 $\mathrm{nm}$ band pass (FL2) filters in a LSR Becton Dickinson flow cytometer. After all the measurements, $10 \mu \mathrm{M}$ A-23187 ionophore (Enzo Life Sciences) was added in order to prove the sensitivity of the assay.

\subsection{Morphological studies by Confocal Microscopy}

For Confocal Microscopy studies, RAW-264.7 macrophagelike cells were cultured for $24 \mathrm{~h}$ on MGHA disks $(10 \mathrm{~mm}$ diameter and $4 \mathrm{~mm}$ high) prepared by uniaxial and isostatic pressure of powder. After fixation with $3.7 \%$ paraformaldehyde in PBS for $10 \mathrm{~min}$, samples were washed with PBS and permeabilized with $0.1 \%$ Triton $\mathrm{X}-100$ for 3 to $5 \mathrm{~min}$. The samples were then washed with PBS and preincubated with PBS containing $1 \% \mathrm{BSA}$ for 20 to $30 \mathrm{~min}$. Then cells were incubated for 20 min with FITC phalloidin which stains F-actin filaments. Samples were then washed with PBS and the cell nuclei were stained with DAPI (4'-6-diamidino-2'phenylindole, $3 \mu \mathrm{M}$ in PBS). After staining and washing with PBS, cells were examined by a LEICA SP2 Confocal Laser Scanning Microscope. The fluorescence of FITC was excited at $488 \mathrm{~nm}$ and the emitted fluorescence was measured at 491-586 $\mathrm{nm}$. The fluorescence of DAPI was excited at $405 \mathrm{~nm}$ and measured at $420-480 \mathrm{~nm}$.

\subsection{Mice}

Mice from C57BL/6 strain were bred under specific pathogenfree conditions in the animal care facility of the Centro Nacional de Microbiología (Instituto de Salud Carlos III, Majadahonda, Madrid, Spain), from stock purchased from Charles River. Sex-matched, 10-12 weeks old mice were used throughout the experiments. All procedures were approved by Institutional Animal Care and Use Committees.

\subsection{Culture and activation of murine spleen cells}

Cell suspensions from C57Bl/6 spleens in Click's culture medium supplemented with $10 \%$ FBS were obtained, and the erythrocytes were lysed by hypotonic shock. Cell suspensions were filtered through 30 microns mesh and washed. In vitro primary stimulation was performed by culturing $5 \times 10^{5}$ cells in
$200 \mu \mathrm{l}$ of Click's medium supplemented with 10\% FBS and $10 \mathrm{mM}$ HEPES, in the presence of Y-CD3-1 (anti-CD3 monoclonal antibody, $5 \mu \mathrm{g} / \mathrm{ml})^{23}$ or Lipopolysaccharide (LPS, E.coli $055: \mathrm{B} 5,25 \mu \mathrm{g} / \mathrm{ml}$ ) as stimuli and in the presence or absence of filtered MGHA extracts. After $3 \mathrm{~d}$ culture at $37^{\circ} \mathrm{C}$ and $5 \% \mathrm{CO}_{2}$, viability measured as mitochondrial activity was assessed by a colorimetric assay using 3-(4,5-dimethylthiazol2-yl)-2,5-diphenyltetrazolium bromide (MTT) as a substrate for mitochondrial dehydrogenases in living cells as previously described by Mosmann. ${ }^{24}$

\subsection{Detection of murine lymphocyte spontaneous} apoptosis

To assess the effect of MGHA scaffolds on murine lymphocyte spontaneous apoptosis, spleen cells were prepared as above but cells were cultured in flat-bottom P-48 culture plates containing previously stabilized scaffolds. $5 \times 10^{6}$ cells were seeded onto the scaffold in a final volume of $0.5 \mathrm{ml}$ culture medium. After $24 \mathrm{~h}$ culture at $37^{\circ} \mathrm{C}$ and $5 \% \mathrm{CO}_{2}$, cells were collected and spontaneous apoptosis was determined by Flow Cytometry in cells stained with AnnexinV-FITC and propidium iodide using the Human Annexin V-FITC kit (eBioscience) according to the manufacturer's instructions and analyzed in a FacsCanto (B-D Biosciences) flow cytometer with DIVA software.

\subsection{Analysis of intracellular cytokine expression}

To analyze the effect of MGHA scaffolds on cytokine expression, suspensions of murine spleen cells were prepared as above. $10^{6}$ cells were seeded onto scaffolds in P-48 culture plates and cultured $3 \mathrm{~d}$ in the presence of Y-CD3-1 (anti-CD3 antibody, $5 \mu \mathrm{g} / \mathrm{mL})$ or LPS $(50 \mu \mathrm{g} / \mathrm{ml})$ or culture medium, in 1 $\mathrm{ml}$ final volume. After this time, cells were collected and processed for intracellular cytokine detection by Fluorescenceactivated cell sorting (FACS). Intracellular cytokine staining was performed essentially as described by Rojo et al. ${ }^{25}$ Cells were washed and re-suspended at $2 \times 10^{6} / \mathrm{ml}$ in culture medium and stimulated with $20 \mathrm{ng} / \mathrm{ml}$ phorboldibutyrate (PDB; SigmaAldrich) plus $1 \mu \mathrm{M}$ ionomycin (Calbiochem) for $1.5 \mathrm{~h}$. Brefeldin A (10 $\mu \mathrm{g} / \mathrm{ml}$; Sigma-Aldrich) was added, and the cells were incubated for further $3.5 \mathrm{~h}$, washed and surface labeled with desired antibodies by incubation for $30 \mathrm{~min}$ on ice with fluorocrome-coupled antibodies diluted in cold staining buffer (PBS containing $2 \%$ FCS and $0.1 \%$ sodium azide). Then, the cells were washed two times and fixed for $5 \mathrm{~min}$ at room temperature with $4 \%$ paraformaldehyde in PBS. After stopping the fixation with ice-cold $0.1 \%$ BSA in PBS/ $0.1 \%$ azide, the cells were washed with $0.1 \%$ saponin (Sigma-Aldrich) in PBS/0.1\% BSA/10mM HEPES/azide (PBS/saponin) and blocked at $4^{\circ} \mathrm{C}$ for $30 \mathrm{~min}$ with $5 \%$ non-fat milk in PBS/saponin. Then, the cells were stained with PE-, Alexa Fluor 647-, DyLight 649 (Pierce)- or FITC-coupled antibodies in 5\% non-fat milkin PBS/saponin for $30 \mathrm{~min}$ in the cold. After washing three times with PBS/saponin, the cells were analyzed in a FACSCanto (B-D Biosciences) flow cytometer. The antibodies for cytokine intracellular detection were from eBioscience: PE-coupled anti-IL-2 (JES6-5H4), and anti-IL-10 (JES5-16E3); FITC-coupled anti-IFN $\gamma$ (XMG 1.2) and antiTNF $\alpha$. As negative controls, PE- or FITC-conjugated isotype control mAb were used.

\subsection{Statistics}

Data are expressed as means \pm standard deviations of a representative of three experiments carried out in triplicate. Statistical analysis was performed using the Statistical Package 
for the Social Sciences (SPSS) version 19 software. Statistical comparisons were made by analysis of variance (ANOVA). Scheffé test was used for post hoc evaluations of differences among groups. In all of the statistical evaluations, $\mathrm{p}<0.05$ was considered as statistically significant.

\section{Results and discussion}

\subsection{MGHA 3D scaffolds}

The new mesoporous glass/hydroxyapatite nanocomposite MGHA has been used as starting material for the manufacturing of the 3D scaffolds by RP technique, as previously has been reported. ${ }^{11}$ Previous results demonstrate its high biocompatibility and bioactivity ${ }^{9,11}$ and drug loading capability, ${ }^{26}$ characteristics which make to MGHA a potential biomaterial for bone tissue engineering. In the present study, hierarchical 3D MGHA scaffolds and their degradation products (extracts) have been prepared to evaluate their effects on immune cells, involving macrophages and lymphocytes.

As it can be observed in Fig. 1, MGHA 3D scaffolds present a hierarchical porous macro-mesoarchitecture which improves cell adhesion, proliferation differentiation and colonization. ${ }^{11}$
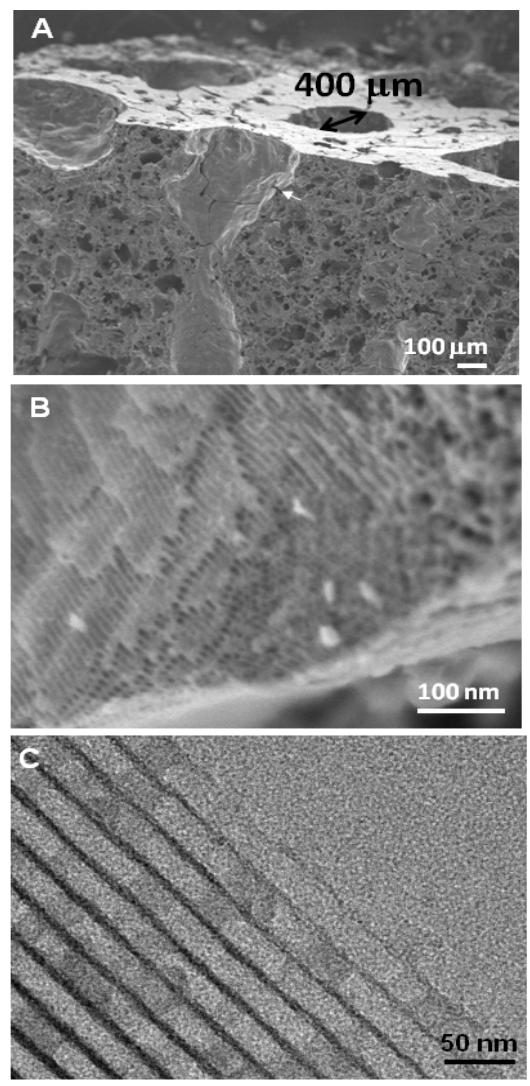

Fig. 1 SEM and TEM studies of the macro and mesostructure of MGHA 3D scaffolds. (A) Cross section of a 3D scaffold showing the hierarchical pore structure of MGHA scaffolds. The small arrow shows the interconnections of large channels of $400 \mu \mathrm{m}$ with the interior. (B) SEM micrograph taken with a JEOL JSM7600F of 3D scaffold surface, showing mesoporous channels typical of a 2D hexagonal structure. (C) TEM image showing a mesoporous arrangement, where the darker zones homogeneously distributed into the mesoporous channels correspond to apatite nanocrystalline phase.
Moreover, these porosity properties can lead to mineralization, vascularisation and nutrient diffusion which are critical for the osteogenesis. ${ }^{27-29}$ Furthermore, the mesoporous arrangement could lead an added value as controlled delivery systems of biologically active molecules. ${ }^{30,31}$

With the aim of evaluating the in vitro degradation of MGHA 3D scaffolds, the surface changes and the evolution of their macroporous structure after different incubation times in culture medium have been studied by SEM (Fig. 2). In the first 24h, the SEM micrographs (Fig. 2D, 2E and 2F) show an early gradual degradation of the surface with small deposits of particles.

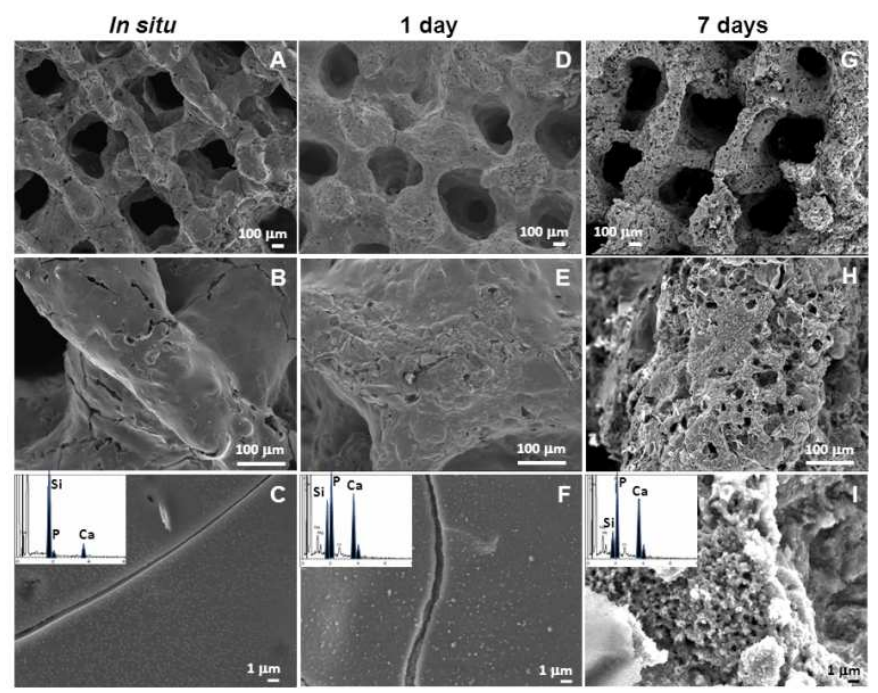

Fig. 2 In vitro degradation test. SEM micrographs at different magnifications and EDS analyses (inset) before (A, B and C) and after $1(\mathbf{D}, \mathbf{E}$ and $\mathbf{F})$ and 7 days $(\mathbf{G}, \mathbf{H}$ and $\mathbf{I})$ soaking in DMEM.

Fig. 3 shows in details this gradual deposition which is formed by needled-like particles typical of apatite formation on bioactive surfaces. ${ }^{29}$ On the other hand, after $7 \mathrm{~d}$, there are substantial changes in the surface and the macroporous architecture of the scaffold (Fig. 2G and 2H), showing a notable degradation from a smooth surface (in situ) to a highly degraded surface which exhibits macroporous in the range of $100-25 \mu \mathrm{m}$. Moreover, SEM higher magnification (Fig. 2I) shows the existence in this surface of acicular particles with a majority composition of $\mathrm{Ca}$ and $\mathrm{P}(\mathrm{Ca} / \mathrm{P}=1.67)$, corresponding to apatite phase, in agreement with other studies. ${ }^{32}$ EDS analyses (inset Fig. 2C, 2F and 2I) confirm both notable increase of the amount $\mathrm{Ca}$ and $\mathrm{P}$ together with a decrease of $\mathrm{Si}$ amount in the scaffold surface after 1 and $7 \mathrm{~d}$ of incubation in DMEM, respectively (Fig. 4). These results evidence the excellent bioactive behaviour, according to previous results in simulated body fluid. ${ }^{9}$

Fig. 4 shows a gradual degradation of 3D scaffolds, exhibiting an initial rapid increase of calcium and phosphorus concentration in the soaking medium in the first $24 \mathrm{~h}$ of incubation. Then, the ionic concentrations slightly increase until $7 \mathrm{~d}$ and remain without variation until 30d. Concerning the silicon variation, the plot shows constant gradual silicon leaching during all period time. Thus, the obtained results reveal a gradual degradation of these 3D MGHA scaffolds over time. 

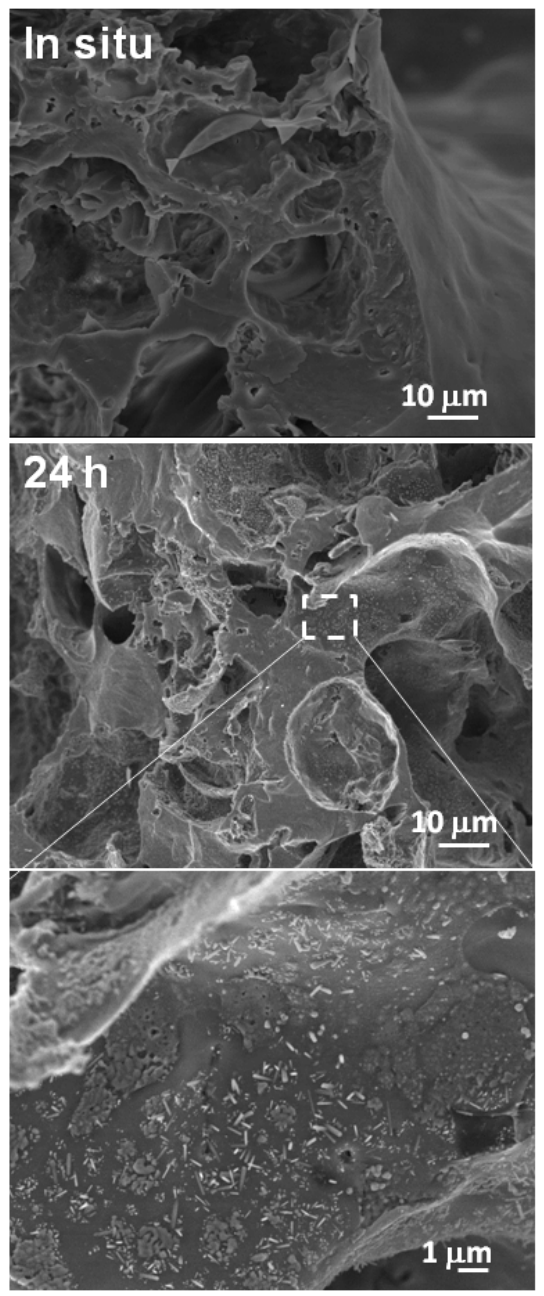

Fig. 3 SEM study of MGHA scaffolds before and after 24 hours of incubation in DMEM. The micrographs show clearly the formation of needled-like aggregated of apatite phase on the scaffolds surface after $24 \mathrm{~h}$.

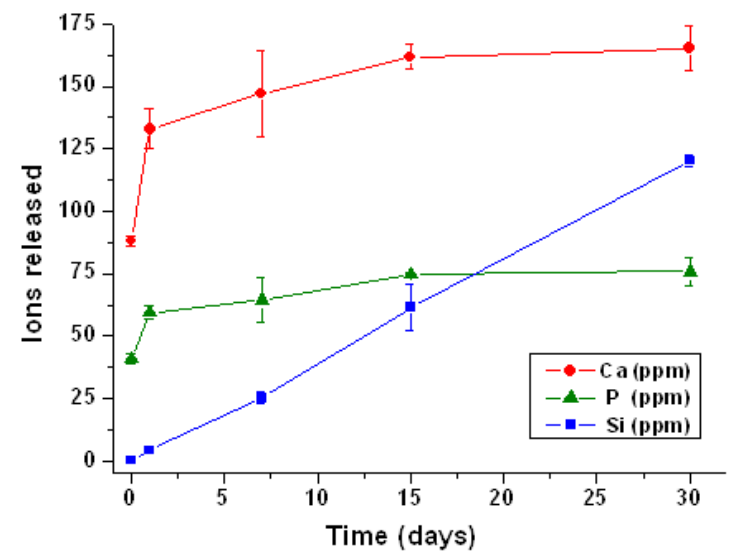

Fig. 4 Variation of the Calcium, Phosphorous and Silicon concentration in DMEM overtime.

FTIR spectroscopy was carried out to evaluate the changes in the MGHA nanocomposite scaffold surface as a function of soaking time in DMEM (Fig. 5). Before soaking, the spectrum shows characteristic absorption bands of $\mathrm{Si}-\mathrm{O}$ bonds at 1040 , 800 , and $470 \mathrm{~cm}^{-1}$. After 24 hours of soaking in DMEM, an increase of the doublet at 560 and $600 \mathrm{~cm}^{-1}$, corresponding to a crystalline phosphate is observed, confirming the formation of a new crystalline phosphate onto the scaffold surface in agreement to SEM-EDS results. Moreover, after $7 \mathrm{~d}$, the spectrum analysis shows clearly the proteins adsorption derived of completed DMEM onto the MGHA surface formed onto newly apatite layer.

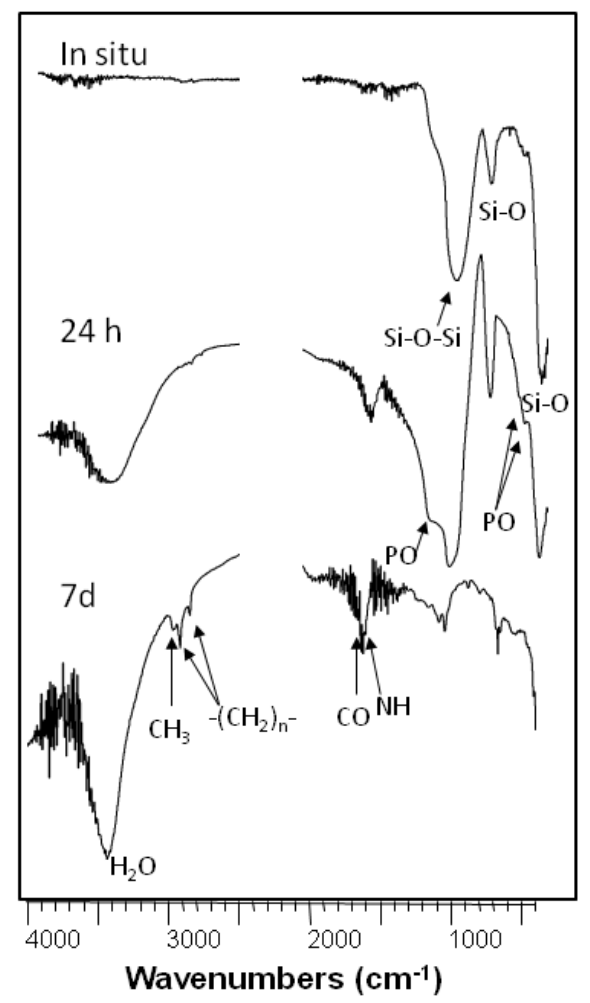

Fig. 5 FTIR spectra corresponding to MGHA scaffolds before and after $24 \mathrm{~h}$ and $7 \mathrm{~d}$ in DMEM.

To evaluate in vitro the response of immune cells to MGHA scaffolds, RAW-264.7 macrophage-like cells and murine spleen cells have been cultured in contact with these samples or their extracts (obtained after $24 \mathrm{~h}$ and $7 \mathrm{~d}$ as described above in section 2.3). These incubation times have been chosen taking into account the higher reactivity of MGHA material at $24 \mathrm{~h}$ and the scaffold degradation/bioactivity observed after $7 \mathrm{~d}$.

\subsection{Effects of MGHA biomaterial on RAW-264.7 macrophage-like cells}

RAW-264.7 macrophage-like cells are functional macrophages with the ability of autophagy and phagocytosis as immune cells and retain many of the characteristics of macrophages in vivo, for these reasons this cell line is usually used for in vitro biocompatibility studies. ${ }^{33}$ Table I shows that no significant changes of cell viability (up $75 \%$ ) were detected by propidium iodide exclusion test after 24h culture of RAW-264.7 macrophage-like cells with MGHA extracts (obtained at $24 \mathrm{~h}$ and 7d; E 24h and E 7d, respectively) or MGHA scaffolds (SC). 
Table I. Effect of MGHA extracts (obtained at 24h and 7d) and MGHA scaffolds (SC) on viability of RAW-264.7 macrophage-like cells after $24 \mathrm{~h}$ treatment. Cells without treatment were cultured in parallel (Control).

\begin{tabular}{|c|c|}
\hline Sample & Viability (\%) \\
\hline Control & $79.3 \pm 2.2$ \\
\hline E 24h & $78.8 \pm 2.8$ \\
\hline E 7d & $82.1 \pm 3.4$ \\
\hline SC & $75.8 \pm 2.1$ \\
\hline
\end{tabular}

When proliferation of RAW-264.7 macrophage-like cells on MGHA scaffolds was evaluated, no alterations were detected in comparison with control samples (Table II). The cell cycle was studied by flow cytometry after culture of these cells on MGHA scaffolds and the SubG $_{1}$ fraction, attributed to cells with fragmented DNA, was used as indicative of apoptosis. ${ }^{34}$ Viable cell number count was used to assess proliferation. As it can be observed in Table II, MGHA samples did not produce changes in $\mathrm{SubG}_{1}$ phase of RAW-264.7 macrophage-like cells, thus indicating that MGHA scaffolds did not induce apoptosis in this cell type which presented apoptosis levels lower than $3 \%$.

Table II. Effect of MGHA scaffolds (SC) on proliferation and apoptosis of RAW-264.7 macrophage-like cells.

\begin{tabular}{|c|c|c|}
\hline Sample & $\begin{array}{c}\text { Proliferation (Cell } \\
\text { number x 10 }\end{array}$ & Apoptosis (\%) \\
\hline Control & $32.2 \pm 6.2$ & $2.81 \pm 0.14$ \\
\hline SC & $30.5 \pm 4.4$ & $2.57 \pm 0.13$ \\
\hline
\end{tabular}

When Confocal Microscopy techniques were carried out to evaluate the RAW-264.7 morphology in contact with MGHA disks, the typical characteristics of these macrophages were observed. Fig. 6 shows that no morphological alterations induced by MGHA material were detected in RAW-264.7 macrophage-like cells which showed intact cytoplasmic filaments of F-actin (Fig. 6, FITC phalloidin labeling in green). DAPI is a DNA dye widely used to visualize the changes of the chromatin in apoptotic cells. This probe stains the cell nuclei and allows detecting the presence of apoptotic bodies produced by the chromatin condensation/fragmentation as a late marker of apoptosis. No apoptotic nuclei were detected in RAW-264.7 macrophage-like cells cultured on MGHA disks in agreement with the low levels of apoptosis detected by flow cytometry (Table II).

The effects of 24h and 7d MGHA extracts and scaffolds on the cell size and complexity of RAW-264.7 macrophage-like cells were also evaluated by Flow Cytometry through FSC and $90^{\circ} \mathrm{SSC}$ light scatter as indicators of cell size and complexity, respectively. These properties are determined in part by cell size, plasma membrane, cytoplasm, mitochondria, pinocytic vesicles, and lysosomes. ${ }^{35}$ As it can be observed in Fig. 7, the contact of RAW-264.7 macrophage-like cells with MGHA scaffolds or their extracts produce a decrease of cell size (Fig. 7A) with a slight increase of macrophage complexity (Fig. 7B).
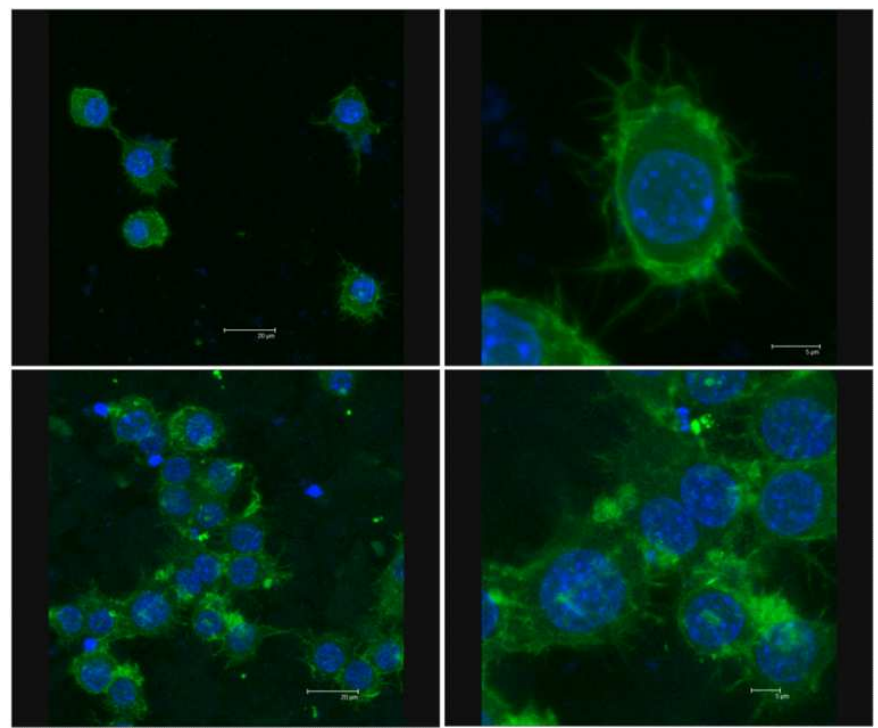

Fig. 6 Morphological evaluation of RAW-264.7 macrophage-like cells on MGHA disks. Cells were stained with DAPI for the visualization of the cell nuclei in blue and with FITC phalloidin for the visualization of cytoplasmic F-actin filaments in green.
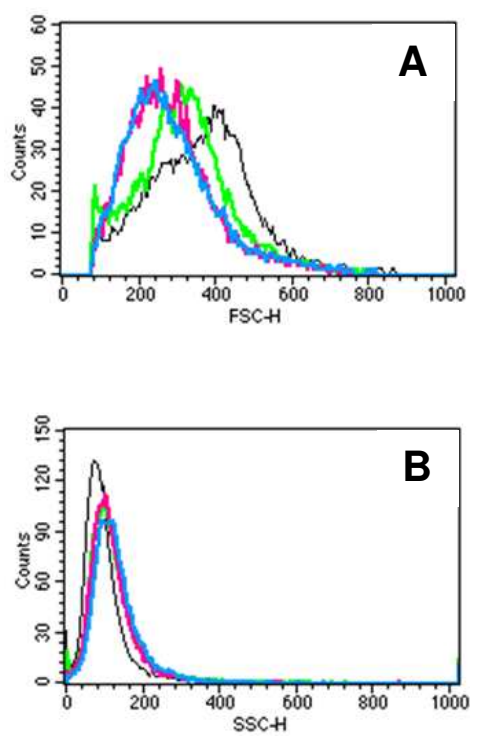

Fig. 7 Effect of MGHA extracts and MGHA scaffolds on light scattering properties of RAW-264.7 macrophage-like cells. (A) Forward angle scatter (FSC, cell size) versus number of cells after treatment with MGHA scaffolds (green), $24 \mathrm{~h}$ extract (pink), and $7 \mathrm{~d}$ extract (blue). (B) 90 side angle light scatter (SSC, internal complexity) versus number of cells after treatment with MGHA scaffolds (green), $24 \mathrm{~h}$ extract (pink), and $7 \mathrm{~d}$ extract (blue).Control cells without treatment (black).

Macrophages are one of the most versatile type of immune cells, carrying out a large number of important functions, essential to both innate and acquired immune responses. These functions include: phagocytosis of apoptotic cells, bacteria, and viruses; production of reactive nitrogen and oxygen species; antigen processing and presentation; and cytokine and chemokine production. ${ }^{15}$ Since reactive oxygen species (ROS) 
and $\mathrm{Ca}^{2+}$ constitute the most important intracellular signaling molecules for the regulation and integration of diverse cellular functions, the effects of MGHA extracts (obtained at 24h and 7d) and MGHA scaffolds (SC) on intracellular ROS content and cytosolic calcium of RAW-264.7 macrophage-like cells after $24 \mathrm{~h}$ treatment were evaluated by flow cytometry with the probes DCFH and Indo-1 respectively. Significant ROS increases $(\mathrm{p}<0.005)$ were produced by $7 \mathrm{~d}$ MGHA extracts and scaffolds (Table III, a.u. = arbitrary units of fluorescence). Concerning intracellular calcium measurements, the probe Indo-1 shifts their spectral characteristics upon calcium binding, from FL1 to $\mathrm{FL} 2 ;^{36}$ ratio FL1/FL2 can be used as an indicator of intracellular $\mathrm{Ca}^{2+}$ content. As it can be observed in Table III, fluorescence ratio of RAW-264.7 macrophage-like cells significantly increased $(\mathrm{p}<0.001)$ after culture with $24 \mathrm{~h}$ and $7 \mathrm{~d}$ MGHA extracts and scaffolds, thus indicating the MGHA extracts and scaffolds induced a significant cytosolic calcium increase of these cells. Several studies have demonstrated that some materials increase $\left[\mathrm{Ca}^{2+}\right]_{i}$ possibly through the entry of extracellular $\mathrm{Ca}^{2+}$ via $\mathrm{Ca}^{2+}$ channels in the plasma membrane, and activate the generation of ROS. ${ }^{37}$

Table III. Effect of MGHA extracts and MGHA scaffolds on intracellular ROS content and intracellular calcium of RAW-264.7 macrophage-like cells.

\begin{tabular}{|c|c|c|}
\hline Sample & ROS (a.u.) & $\mathbf{C a}_{\mathbf{i}}\left(\mathbf{F L}_{\mathbf{1}} / \mathbf{F L}_{\mathbf{2}}\right)$ \\
\hline Control & $476 \pm 23.8$ & $1.70 \pm 0.09$ \\
\hline E 24h & $471 \pm 23.6$ & $2.47 \pm 0.12$ \\
\hline E 7d & $606 \pm 30.3$ & $2.36 \pm 0.12$ \\
\hline SC & $611 \pm 30.6$ & $2.45 \pm 0.12$ \\
\hline
\end{tabular}

Macrophages play a central role in directing the host response to implanted biomaterials, including the inflammatory response and the reparative response with an M1 and M2 phenotypic spectrum. ${ }^{17-22}$ Since several studies have demonstrated that M1 macrophages produce and secrete higher ROS levels than M2 cells, ${ }^{17,38}$ the effects of MGHA extracts or MGHA scaffolds on populations of RAW-264.7 macrophagelike cells with low and high intracellular ROS content have been evaluated by Flow Cytometry in the present study. Fig. 8 shows the profiles of cell number (counts) versus DCF fluorescence (FL1) used as indicative of intracellular ROS. Macrophages in contact with MGHA scaffolds (Fig. 8B) and control macrophages (Fig. 8A) showed different intracellular ROS profiles. Fig. 9 shows that in the presence of $24 \mathrm{~h}$ extracts, the population with low ROS content is significantly higher than the population with high ROS content, in agreement with the results presented in Table III which indicates no high intracellular ROS levels when RAW macrophage-like cells are cultured with these extracts. This effect can be related to the rapid release of ions (calcium, phosphorous and silicon) to the medium in the early steps of the reactivity/bioactivity process (Fig. 4). On the other hand, 7d MGHA extract does not induce changes on the percentages of low and high ROS populations probably due to the stabilization of this release which is slower at this time (Fig. 4). The direct contact of RAW-264.7 macrophage-like cells with the MGHA scaffolds during 24h increases both the intracellular ROS content (Table III) and subsequently the high ROS content population in comparison with control, thus indicating the high reactivity/bioactivity of the surface-level of MGHA scaffolds previously observed in Fig. 3 and Fig. 4.
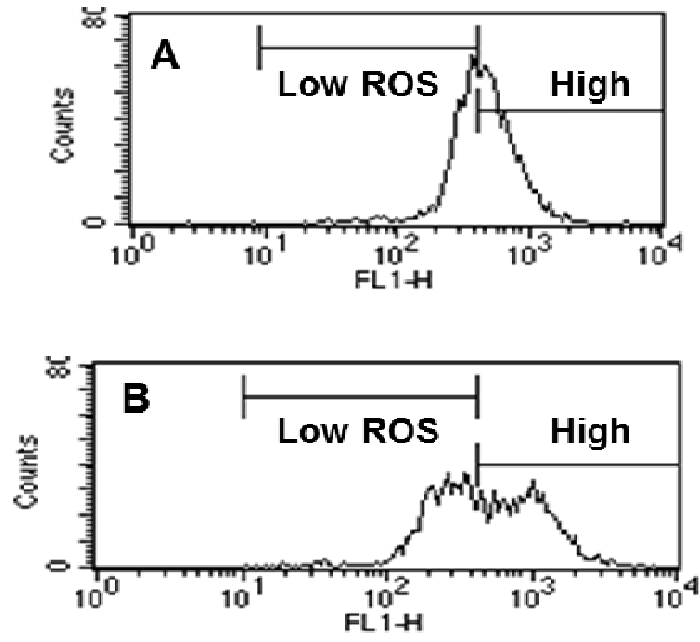

Fig. 8 Effect of MGHA scaffolds on populations of RAW-264.7 macrophage-like cells evaluated through intracellular ROS (Flow Cytometry profiles). Intracellular ROS (FL1, a.u.) versus number of cells after treatment with MGHA scaffolds (B). Control untreated cells (A).

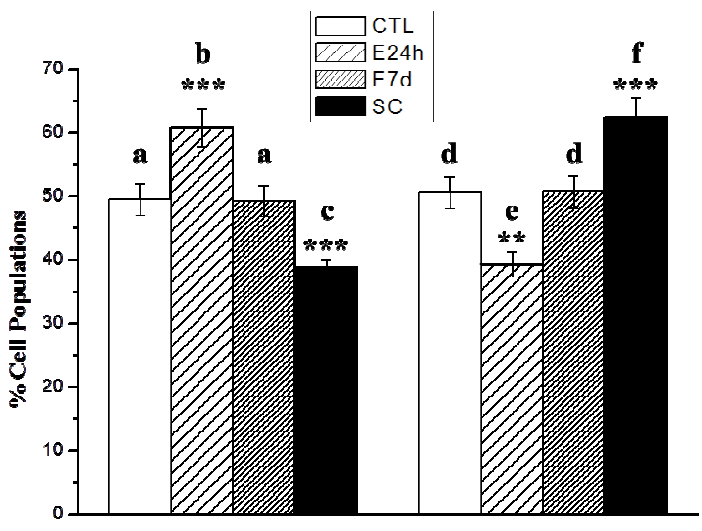

Low ROS

High ROS

Fig. 9 Effect of MGHA extracts and MGHA scaffolds on the percentage of populations of RAW-264.7 macrophage-like cells with low and high intracellular ROS content. CTL $=$ Control untreated cells. Columns with different letters are statistically different. Statistical significance $* * \rho<0.01 ; * * * \rho<0.005$.

\subsection{Effects of MGHA biomaterial on murine spleen cell suspensions}

Immune response plays a determinant role in the tolerance to and functioning of biomaterials. Immune system is composed of many different subpopulations which mutually interact and cross-talk determining the final outcome of the immune response. To assess the potential effect of MGHA on immune cells, we chose to analyze its effect on murine spleen cell suspensions, an in vitro system in which different untransformed normal cell subpopulations interact in among them, better resembling the in vivo ambient. The spleen is a lymphoid organ which contains different types of immune cells, 
mainly including $\mathrm{T}$ - and B-lymphocytes (about $80 \%$ in the mouse spleen), macrophages and other antigen-presenting (APC) (about 10\%) and natural killer (NK) cells. These cells circulate through the body monitoring for signals which trigger an innate response or detecting non-self antigens, thus becoming activated, differentiated and expanded, mounting an acquired immune response. The contact of body fluids and blood cells with biomaterials may trigger the activation of granulocytes, monocytes and macrophages, driving to an acute and lately chronic inflammatory response. Although the biomaterial composition does not allow $\mathrm{T}$ cell activation via antigen presentation, it has been suggested that synthetic biomaterials may present functional groups on their surfaces acting as mitogens which can trigger lymphocytes by crosslinking of glycoproteins on the cell surface. ${ }^{15} \mathrm{We}$ assessed this possibility studying the effect of MGHA extracts and scaffolds on murine normal and activated immune cells.

3.3.1. MGHA biomaterial does not alter murine lymphocyte activation or spontaneous apoptosis. To evaluate the biocompatibility of MGHA on murine spleen immune cells, we firstly assayed the in vitro effect of $24 \mathrm{~h}$ biomaterial extracts, analysing any potential cytotoxic or immunomodulatory effect of the biomaterial components released to the medium. The MGHA extracts were added to cell suspensions of murine spleen cells in an in vitro activation assay in the absence or the presence of anti-CD3 antibody $(5 \mu \mathrm{g} / \mathrm{ml})$ or LPS $(25 \mu \mathrm{g} / \mathrm{ml})$ as mitogens. Cell activation was measured $72 \mathrm{~h}$ later as mitochondrial activity (Fig. 10). Cell subpopulations became activated and proliferated in the presence of these stimuli, while cells in the control cultures (CTL) did not, even when MGHA extracts had been added to the cultures, indicating that no mitogen activity for immune cells is present in this biomaterial extract. No significant modification of cell activation was detected in control or mitogen-treated cultures in the presence of MGHA extracts. This assay also shows that the viability in the cultures was not modified in the presence of different proportions of MGHA extracts. We further analyzed the effect of MHGA-lymphoid cell contact by studying apoptosis of different lymphoid subpopulations in the presence of MGHA scaffolds. Spleen cells were seeded onto scaffolds and incubated during $24 \mathrm{~h}$ before analyzing spontaneous apoptosis.

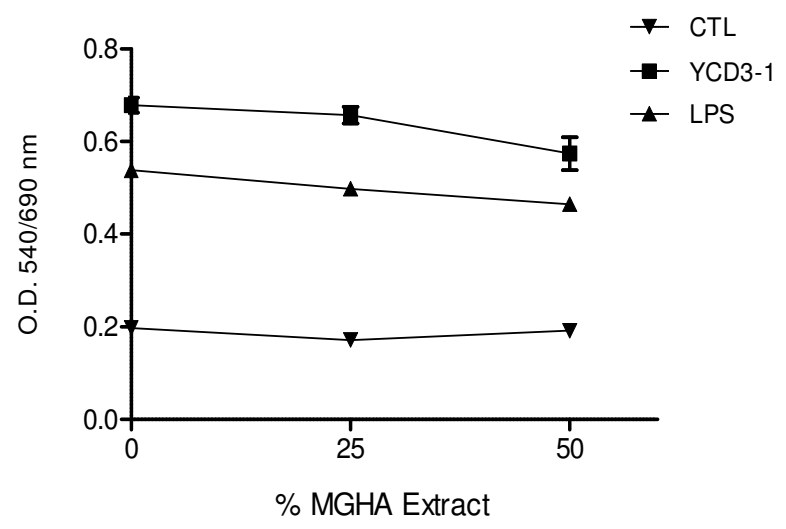

Fig. 10 Effect of MGHA extracts on murine spleen cell activation. The effect of two different concentrations of MGHA extract was evaluated in an activation assay in the presence of anti-CD3 antibody (YCD3-1, T-cell mitogen, squares), LPS (B-cell mitogen, triangles) or medium (control, CTL, inverted triangle). Mitochondrial activity was measured after 72 hours culture and represented as O.D.
Fig. 11 shows that no significant modification of spontaneous apoptosis ( $p>0.05$ in all cases) was induced by MGHA scaffolds in $\mathrm{T}\left(\mathrm{CD}^{+}, \mathrm{CD}^{+}, \mathrm{CD}^{+}\right)$or $\mathrm{B}\left(\mathrm{CD} 19^{+}\right)$lymphocytes, natural killer $\left(\mathrm{NK} 1.1^{+}, \mathrm{GR} 1^{+}, \mathrm{CD} 11 \mathrm{~b}^{+}\right)$or monocytesmacrophages $\left(\mathrm{CD} 11 \mathrm{~b}^{+}\right)$subpopulations in the spleen cell cultures. GR1 is also a marker for the low proportion of peripheral granulocytes found in the spleen which did not result affected by MGHA in this assay.

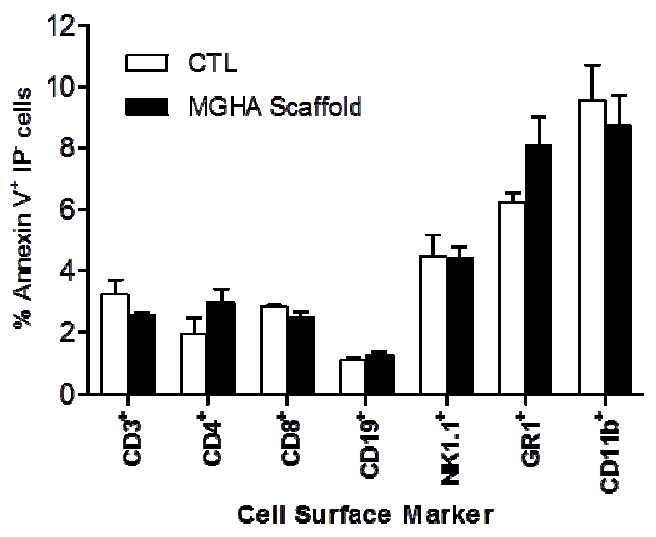

Fig. 11 MGHA scaffolds do not affect spontaneous apoptosis of different spleen cell subpopulations. Apoptosis was measured as percent of Annexin $\mathrm{V}^{+}$Propidium Iodide cells by FACS in murine spleen cells which were seeded onto MGHA scaffolds (filled bars) or directly in the culture wells (CTL, empty bars) and cultured overnight.

3.3.2. MGHA biomaterial does not affect the subpopulations balance or cytokine expression in activated murine immune cells. Activation of normal resting lymphocytes promotes their differentiation to different phenotypes of effector subpopulations and expression of specific cytokines. In $\mathrm{T}$ lymphocytes and macrophages coculture it has been found that $\mathrm{T}$ cells are attached predominantly to macrophages and not to the biomaterial surface, promoting macrophage adhesion and fusion via paracrine effects mediated by different cytokines. ${ }^{39}$ To further study the potential effect of the biomaterial in these processes we analyzed the effect of MGHA scaffolds in the balance of lymphoid subpopulations (measured by specific surface markers) and cytokine secretion (measured as intracellular interleukin expression). Fig. 12A shows that the frequency of different $\mathrm{T}$ cells subpopulations was not significantly altered by the presence of MGHA scaffold during the activation process mediated by $\mathrm{T}$ cell stimulus (anti-CD3 antibody) on spleen cells cultures. The frequency of total $\mathrm{T}$ cells $\left(\mathrm{CD}^{+}\right)$, helper $\left(\mathrm{CD} 4^{+}\right)$ or cytotoxic $\left(\mathrm{CD}^{+}\right)$was evaluated. $\mathrm{T}$ activated cells were identified by CD25 and/or ICOS markers, in total $\mathrm{T}$ or in among $\mathrm{CD}^{+}$or $\mathrm{CD}^{+}$subpopulations showing no significant alteration of these subpopulations mediated by MGHA scaffolds. The use of a higher concentration of YCD3-1 (10 $\mu \mathrm{g} / \mathrm{ml}$ ) for activation did not yield a different effect of the biomaterial extracts (data not shown). Natural $\mathrm{CD} 4{ }^{+} \mathrm{CD} 25^{+} \mathrm{Foxp}^{+} \mathrm{T}$ regulatory cells play a very important role in controlling activation and effector functions of different lymphoid cells, and a disbalance in this subpopulation may cause lymphoproliferative and inflammatory disorders. Thus, we also analyzed the potential effect of MGHA scaffolds on T regulatory cells, but the frequency of natural Treg in activated cultures was not changed in the presence of MGHA scaffolds 
(Fig. 12A). The potential effect of MGHA scaffolds was also assessed in LPS-stimulated spleen cells. Again, the frequency of B lymphocytes $\left(\mathrm{CD} 19^{+}\right)$, macrophages $\left(\mathrm{CD} 11 \mathrm{~b}^{+}\right)$or ICOSligand expressing cells remained unaltered in the presence of MGHA as shown in Fig. 12B. The use of a higher concentration of LPS $(50 \mu \mathrm{g} / \mathrm{ml})$ for activation did not yield a different effect of the biomaterial extracts (data not shown).
A

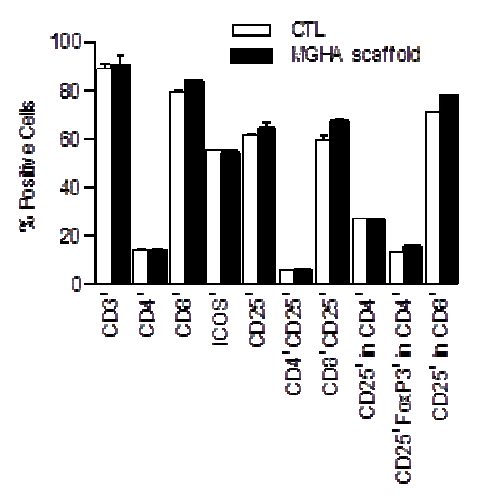

B

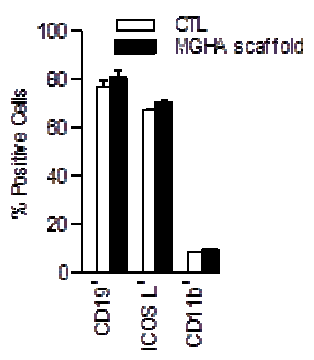

Fig. 12. MGHA scaffolds do not affect the subpopulations in a murine spleen cells activation assay. Percentage of different spleen cell subpopulations (indicated in the $\mathrm{X}$ axis) was evaluated by FACS analysis after 72 hours culture under T- (anti-CD3 antibody) (A) or Bcell stimulus (LPS) (B) in the presence (filled bars) or absence (CTL, empty bars) of MGHA scaffolds.

Cytokine expression and secretion constitute an important effector mechanism of immune cells, determining subsequent activation or suppression of other subpopulations. In among them, we chose to analyse IL-2, IL-10, IFN $\gamma$ and TNF $\alpha$ because of their important implication in the immune response and inflammation. IL-2 is a Th1 cytokine that plays a central role in the activation, proliferation and differentiation of Ag-primed $\mathrm{T}$ lymphocytes. ${ }^{40,41}$ It also modulates the expression of IFN $\gamma$ and MHC antigens, stimulates proliferation and differentiation of activated B cells and augments NK cell activity. IL-10 is an anti-inflammatory Th2 cytokine that has a critical role in limiting the immune response to prevent host damage. ${ }^{42}$ It is expressed by Th2, Th17, T regulatory and B cells, as well as innate immune cells as dendritic cells, macrophages, mast cells, NK, eosinophils and neutrophils. As IL-10 is produced in several $\mathrm{T}$ helper populations, it is proposed that it provides a feedback loop to limit the effector function of macrophages and dendritic cells. IFN- $\gamma$ (Type-II Interferon) is produced by activated T, B and NK cells. During infection is produced by cytotoxic $\mathrm{CD}^{+} \mathrm{T}$ cells and $\mathrm{Th} 1$, inhibiting the proliferation of Th2 phenotype subpopulation. IFN $\gamma$ acts in synergy with other cytokines including TNF $\alpha$ to inhibit the proliferation of normal or transformed cells but also activates monocytes, macrophages, NK and neutrophils. IFN $\gamma$ is a marker for a number of different pathological situations including infections, autoimmune diseases, transplant rejection and diabetes. ${ }^{43,44}$ TNF- $\alpha$ (Tumor Necrosis Factor alpha) is a pleiotropic cytokine that plays a role in innate and adaptive immunity. ${ }^{45}$ Though it is widely implicated in numerous immune responses and regulations, it is most often associated with regulation of cell survival and pro-inflammatories properties which lead to the recruitment and activation of inflammatory cells to the site of injury where it is known to induce various cytokines, including IL-1, IL-6, IL-8, MCP-1 and RANTES. TNF- $\alpha$ is primarily expressed by macrophages, but also by activated lymphocytes, NK cells and neutrophils in among others. It is associated with numerous inflammatory illnesses and autoimmunity. To analyze the potential secondary effect of MGHA on immune cells we studied the intracellular expression of IL-2, IL-10, IFN- $\gamma$ or TNF- $\alpha$ in spleen cell cultures which were activated by mitogens during $72 \mathrm{~h}$. Cytokine expression was analysed in total spleen cells or $\mathrm{CD}^{+}$or $\mathrm{CD}^{+} 9^{+}$subpopulations. No significant effect $(p>0.05)$ of MGHA scaffolds on the intracellular cytokine expression was detected in the analysed cell populations under T- (Fig. 13A) or APC-activating conditions (Fig. 13B). The absence of significant changes in IL-2 and IFN $\gamma$ expression in the presence of the scaffolds indicates the lack of MGHA effects on $T$ cells (Fig. 13). In parallel the absence of significant changes in TNF- $\alpha$ or IL-10 expression indicates that pro- or anti-inflammatory loops are not significantly modified by MGHA scaffolds in T- or APCstimuli conditions (Fig. 13A and B).
A

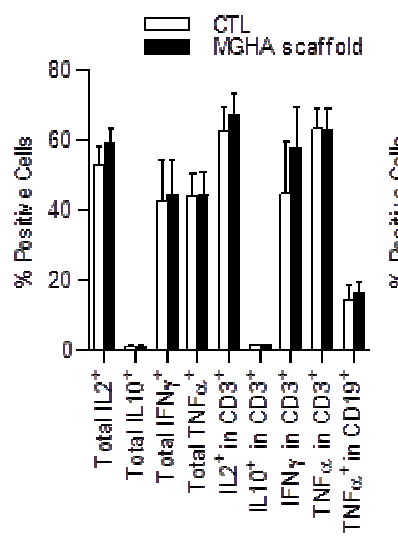

B

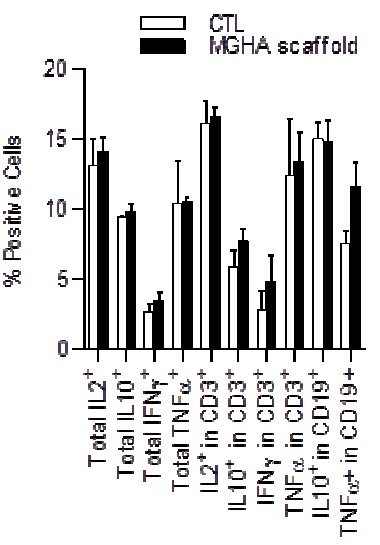

Fig. 13. MGHA biomaterial does not affect the cytokine expression in activated murine immune cells. Percent of cytokine positive spleen cells (indicated in the $\mathrm{X}$ axis) was evaluated by FACS analysis after 72 hours culture under T- (anti-CD3 antibody) (A) or B-cell stimulus (LPS) (B) in the presence (filled bars) or absence (CTL, empty bars) of MGHA scaffolds.

Adjuvant properties of mesoporous silica nanoparticles have been recently shown in several experimental models, producing different effects which depend on the size and functionalization of the particles. ${ }^{46-48}$ In this sense, amino-functionalized MCM41 (AM-41) has been used as a vaccine delivery vehicle and adjuvant in mice using ovalbumin as a model protein antigen. ${ }^{48}$ AM-41 nanoparticles showed adjuvant behaviour and elicited immune responses at reduced antigen doses in vivo. However, there were no local or systemic negative effects in animals injected with AM-41. ${ }^{48}$ In the present study, MGHA scaffolds do not stimulate a significant inflammatory response in vitro. The absence of MGHA immunogenic activity might be explained considering the morphology of the samples (which 
are scaffolds and not nanoparticles) and the different evaluation models.

\section{Conclusions}

Some modifications are induced by MGHA nanocomposite on RAW macrophage-like cells after contact with the scaffold surface or with $24 \mathrm{~h}$ extracts, which can be related to the high reactivity/bioactivity of this nanocomposite. However, MGHA material does not produce significant in vitro alterations in the activation of macrophages, B- or T-lymphocytes and natural killer cells when an immune response stimulation model was carried out using murine primary immune cell subpopulations. Since the MGHA scaffolds are good supports for adhesion, proliferation and differentiation of preosteoblasts, and they would not stimulate a significant inflammatory response, the present study supports the biocompatibility of MGHA material and suggests an adequate host tissue response to their scaffolds upon their implantation.

\section{Acknowledgements}

This study was supported by research grants from Comunidad de Madrid (S2009/MAT-1472), and Ministerio de Economía y Competitividad (MINECO) (research grants MAT2012-35556, CS2010-11384-E and FIS PI10/0648). Mónica Cicuéndez is grateful to MICINN for the financial support through FPI fellowship. The authors wish to thank also to the staff of the ICTS Centro Nacional de Microscopia Electrónica (Spain) and Centro de Citometría y Microscopia de Fluorescencia. The authors thank to Dr. Shunsuke Asahina (SMBU, JEOL, Akishima, Tokyo 196-8558, Japan) and Prof. Osamu Terasaki (Graduate School of EEWS, WCU, KAIST, Daejeon, Republic of Korea) for their help in the tuning of JEOL JSM7600F microscope in the ICTS (http://www.cnme.es) and capture of the micrographs.

\section{Notes and references}

${ }^{a}$ Departamento de Química Inorgánica y Bioinorgánica. Facultad de Farmacia. Universidad Complutense de Madrid. Plaza Ramón y Cajal s/n. 28040 Madrid. Spain.

${ }^{b}$ Networking Research Center on Bioengineering, Biomaterials and Nanomedicine (CIBER-BBN), Madrid, Spain.

${ }^{c}$ Consejo Superior de Investigaciones Científicas, CSIC, Spain

${ }^{d}$ Centro Nacional de Microbiología, Instituto de Salud Carlos III, Majadahonda, 28220-Madrid, Spain

e Departamento de Bioquímica and Biología Molecular I, Facultad de Ciencias Químicas, Universidad Complutense de Madrid, Ciudad Universitaria s/n, 28040-Madrid, Spain.

* Corresponding author: E-mail address: portoles@quim.ucm.es, vallet@ucm.es.

1 R. Langer, J.P. Vacanti. Science 1993, 260, 920-926.

2 T.G. Kim, H. Shin, D.W. Lim. Adv. Funct. Mater. 2012, 22, $2446-$ 2468.

3 F.J. O'Brien. Materials Today 2011, 14, 88-95.
4 S.K. Misra, T.I. Ansari, S.P. Valappil, D. Mohn, S.E. Philip, W.J. Stark, I. Roy, J.C. Knowles, V. Salih, A.R. Boccaccini. Biomaterials 2010, 31, 2806-2815.

5 X. Wang, G. Song, T. Lou. Med. Eng. Phys. 2010, 32, 391-397.

6 M.T. Arafat, C.X.F. Lam, A.K. Ekaputra, S.Y. Wong, X. Li, I. Gibson. Acta Biomater. 2011, 7, 809-820.

7 M. Ebrahimian-Hosseinabadi, F. Ashrafizadeh, M. Etemadifar, S.S. Venkatraman. Polym. Deg. Stab. 2011, 96, 1940-1946.

8 X.Y. Lu, T. Qiu, X.F. Wang, M. Zhang, X.L. Gao, R.X. Li, X. Lu, J. Weng. Appl. Surf. Sci. 2012, 262, 227-230.

9 M. Cicuéndez, M.T. Portolés, I. Izquierdo-Barba, M. Vallet-Regí. Chem. Mater. 2012, 24, 1100-1106.

10 M. Alcaide, M.T. Portolés, A. López-Noriega, D. Arcos, M. ValletRegí. Acta Biomater. 2010, 6, 892-899.

11 M. Cicuéndez, M. Malmsten, J.C. Doadrio, M.T. Portolés, I. Izquierdo-Barba, M. Vallet-Regí. J. Mater. Chem. B. 2014, 2, 4958.

12 S. Hollister. Adv. Mater. 2009, 21, 3330-3342.

13 D.W. Hutmacher. Biomaterials 2000, 21, 2529-2543.

14 A. Remes, D.F. Williams. Biomaterials 1992, 13, 731-743.

15 S. Franz, S. Rammelt, D. Scharnweber, J.C. Simon. Biomaterials 2011, 32, 6692-6709.

16 M.J. Smith, K.L. White, D.C. Smith, G.L. Bowlin. Biomaterials 2009, 30, 149-159.

17 B.N. Brown, B.D. Ratner, S.D. Goodman, S. Amar, S.F. Badylak. Biomaterials 2012, 33, 3792-3802.

18 D.M. Mosser, J.P. Edwards. Nat. Rev. Immunol. 2008, 8, 958-969.

19 B.N. Brown, R. Londono, S. Tottey, L. Zhang, K.A. Kukla, M.T. Wolf, K.A. Daly, J.E. Reing, S.F. Badylak. Acta Biomater. 2012, 8, 978-987.

20 P.M. Kou, J.E. Babensee. J. Biomed. Mater. Res. 2010, 96A, 239260.

21 K. Garg, N.A. Pullen, C.A. Oskeritzian, J.J. Ryan, G.L. Bowlin. Biomaterials 2013, 34, 4439-4451.

22 R.M. Boehler, J.G. Graham, L.D. Shea. BioTech. 2011, 51, 239-254.

23 P. Portolés, J.M. Rojo, A. Golby, M. Bonneville, S. Gromkowski, L. Greenbaum, C.A. Janeway, D.B. Murphy. J. Immunol. 1989, 142, $4169-4175$.

24 T. Mosmann. J. Immunol. Methods 1983, 65, 55-63.

25 J.M. Rojo, E. Pini, G. Ojeda, R. Bello, C. Dong, R.A. Flavell, U. Dianzani, P. Portolés. Int. Immunol. 2008, 20, 577-589.

26 M. Cicuéndez, I. Izquierdo-Barba, M.T. Portolés, M. Vallet-Regí. Eur. J. Pharm. Biopharm. 2013, 84, 115-124.

27 M. Vallet-Regí, J.M. González-Calbet. Prog. Solid. State Sci. 2004, 3, $1-31$.

28 J.R. Jones. Acta Biomater. 2013, 9, 4457-4486.

29 M. Vallet-Regí, M. Colilla, I. Izquierdo-Barba J. Biomed. Nanotech. 2008, 4, 1-15.

30 M. Vallet-Regí. ISRN Mater. Sci. 2012. Article ID 608548, 20 pages.

31 M. Vallet-Regí. J. Intern. Med. 2010, 267, 22-43.

32 M. Vallet-Regí, C.V. Ragel, A.J. Salinas. Eur. J. Inorg. Chem. 2003, 6, 1029-1042.

33 H. Kim, B. Cheon, Y.H. Kim, S.Y. Kim, H.P. Kim. Biochem. Pharm. 1999, 58, 759-765.

34 M. Alcaide, M.C. Serrano, R. Pagani, S. Sánchez-Salcedo, M. Vallet-Regí, M.T. Portolés. Biomaterials 2009, 30, 45-51. 
35 J.M. Udall, R.A. Moscicki, F.I. Preffer, P.D. Ariniello, E.A. Carter, A.K. Bhan, K.J. Bloch. Adv. Exp. Med. Biol. 1987, 216, 821-827.

36 G. Grynkiewicz, M. Poenie, R.Y. Tsien. J. Biol. Chem. 1985, 260, 3440-3450.

37 F. Tian, T. Zhu, Y. Shang. Toxicol. App. Pharm. 2010, 242, 173-181.

38 S. Franz, F. Allenstein, J. Kajahn, I. Forstreuter, V. Hintze, S. Möller. Acta Biomater. 2013, 9, 5621-5629.

39 W.G. Brodbeck, M. Macewan, E. Colton, H. Meyerson H, J.M. Anderson. J. Biomed. Mater. Res. A 2005, 74A, 222-229.

40 S.L. Gaffen, K.D. Liu. Cytokine 2004, 28, 109-123.

41 J. Banchereau, V. Pascual, A. O'Garra. Nat. Immunol. 2012, 13, 925-931.

42 M. Saraiva, A. O’Garra. Nat. Rev. Immunol. 2010, 10, 170-181.

43 K. Schroder, P.J. Hertzog, T. Ravasi, D.A. Hume. J. Leukoc. Biol. 2004, 75, 163-189.

44 L.C. Platanias. Nat. Rev. Immunol. 2005, 5, 375-386.

45 M. Croft. Nat. Rev. Immunol. 2009, 9, 271-285.

46 H. Vallhov, N. Kupferschmidt, S. Gabrielsson, S. Paulie, M. Strømme, A.E. Garcia-Bennett, A. Scheynius. Small. 2012, 8, 21162124.

47 X. Wang, X. Li, A. Ito, Y. Sogo, T. Ohno. Acta Biomater. 2013, 9, 7480-7489.

48 D. Mahony, A.S. Cavallaro, F. Stahr, T.J. Mahony, S.Z. Qiao, N. Mitter. Small. 2013, 9, 3138-3146. 


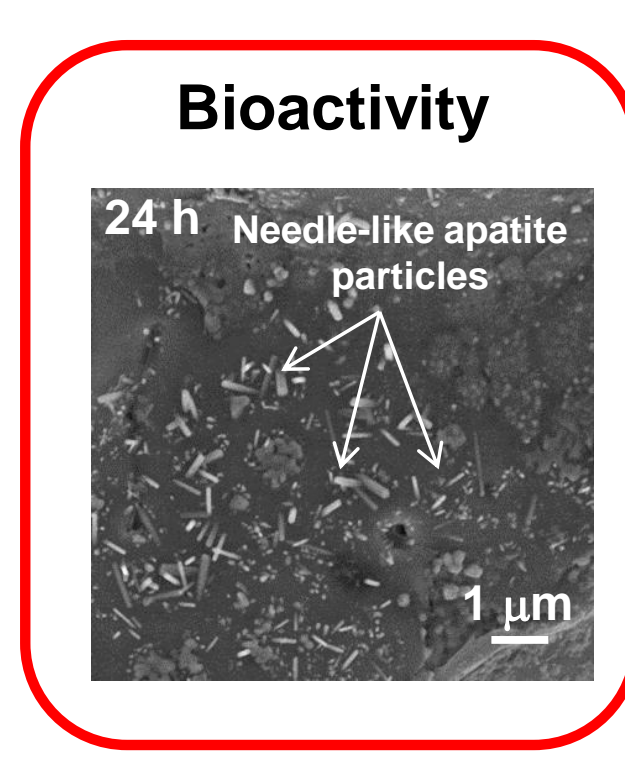

Journal of Materials Chemistry B
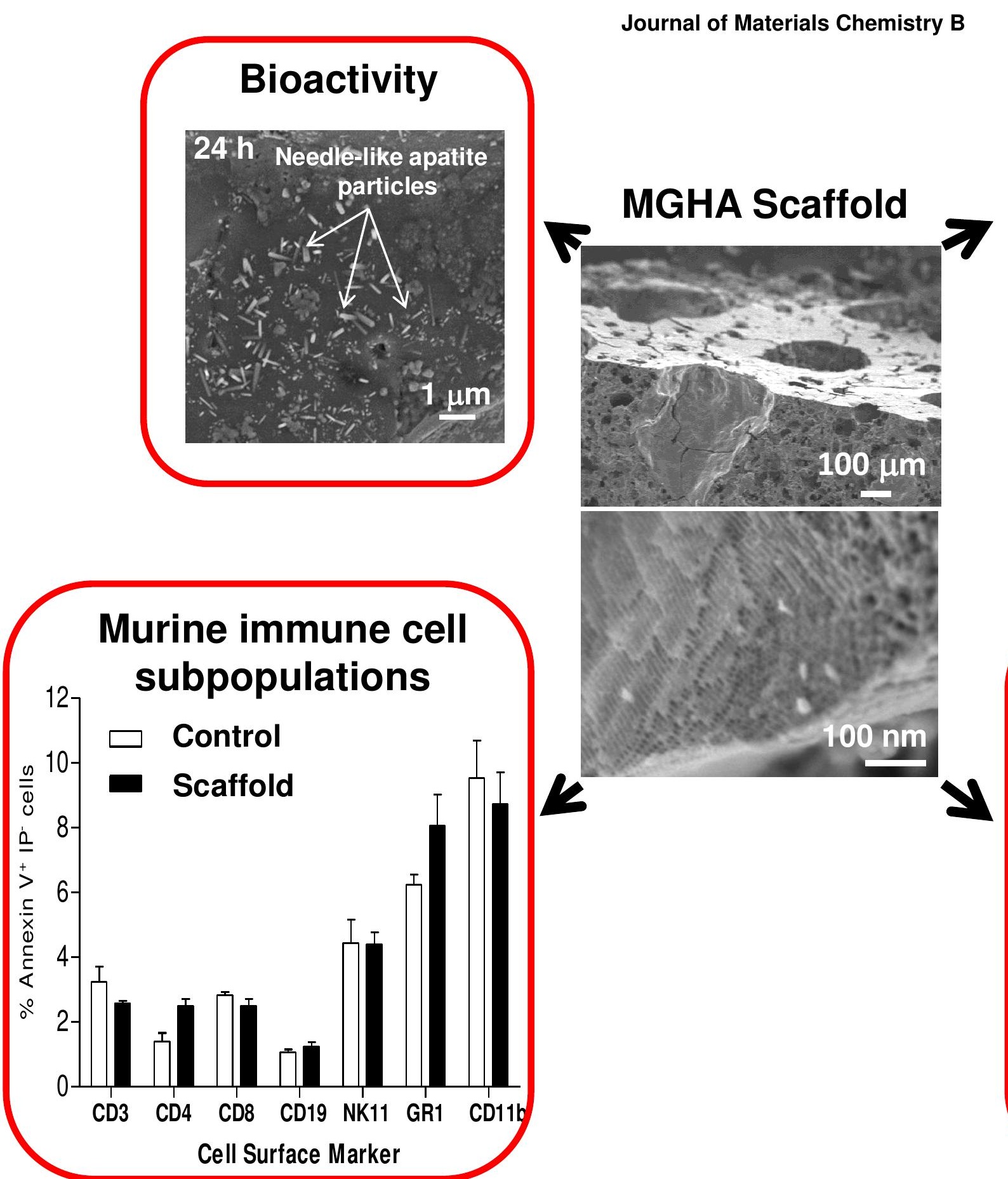

Macrophage adhesion

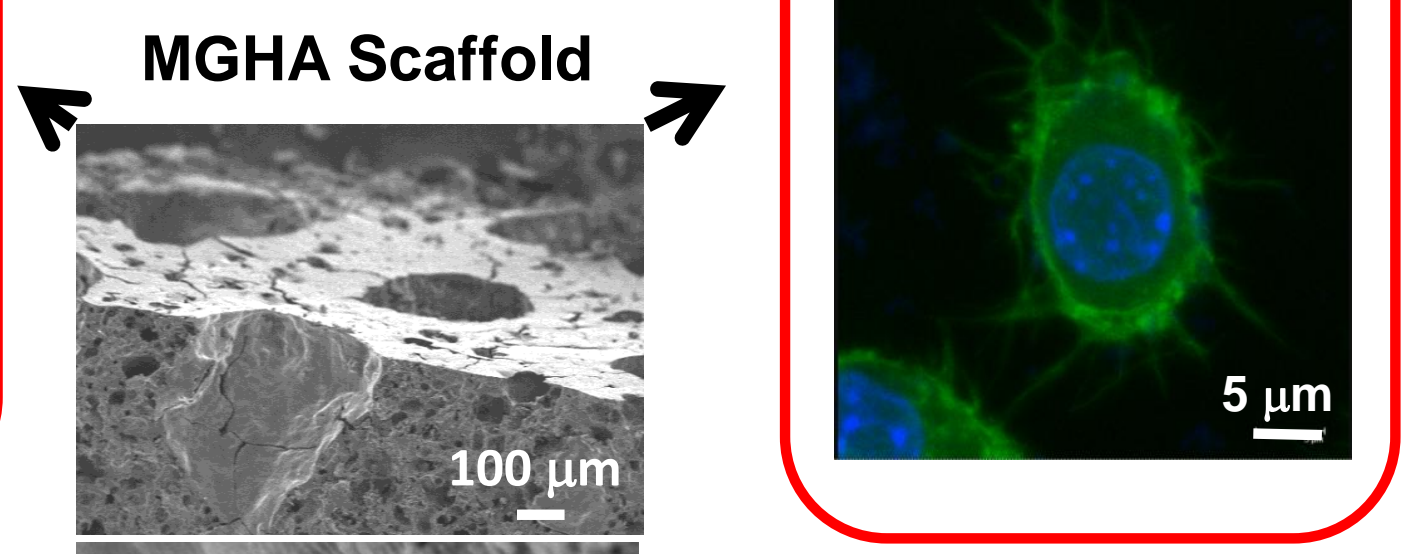

Macrophage populations

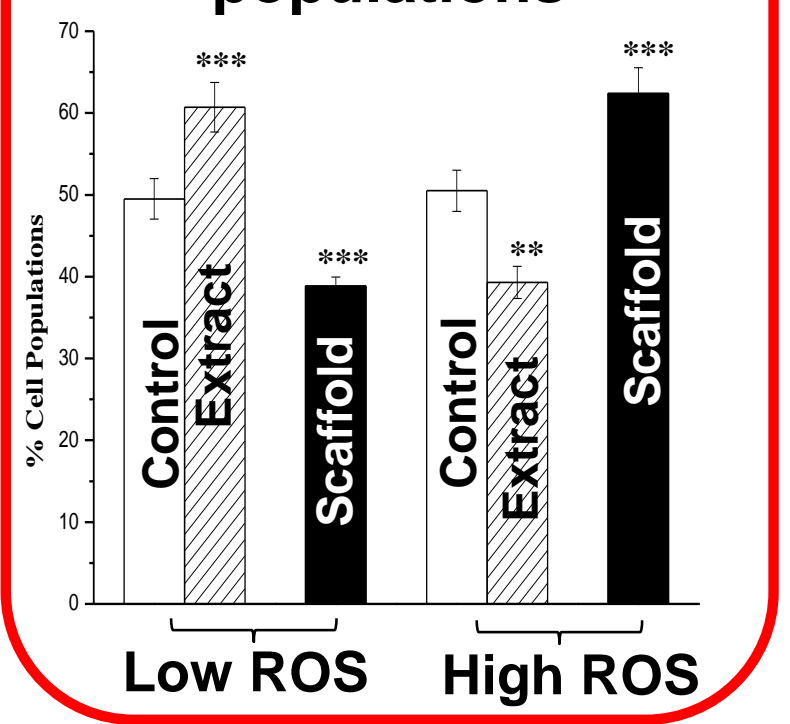

